\title{
Correction to: Synergistic effects of curcumin with emodin against the proliferation and invasion of breast cancer cells through upregulation of miR-34a
}

\author{
Jiaoli Guo ${ }^{1,2} \cdot$ Wenping $\mathrm{Li}^{3} \cdot$ Hongliu Shi ${ }^{2} \cdot \mathrm{Xinhua}_{\mathrm{Xie}^{1,2}} \cdot$ Laisheng $\mathrm{Li}^{4} \cdot$ Hailin Tang ${ }^{1,2} \cdot$ Minqing $\mathrm{Wu}^{1,2}$. \\ Yanan Kong ${ }^{1,2} \cdot$ Lu Yang $^{1,2} \cdot$ Jie Gao $^{1,2} \cdot$ Peng Liu ${ }^{1} \cdot$ Weidong Wei ${ }^{1} \cdot$ Xiaoming Xie $^{1,2}$
}

Published online: 15 December 2021

(c) Springer Science+Business Media, LLC, part of Springer Nature 2021

\section{Correction to: Mol Cell Biochem (2013) 382:103-111 https://doi.org/10.1007/s11010-013-1723-6}

In the original publication of the article, Fig. 3 was published incorrectly. The correct version of Fig. 3 is provided in this correction.

Weidong Wei

weiwd@sysucc.org.cn

$\triangle$ Xiaoming Xie

xiexm@sysucc.org.cn

1 Department of Breast Oncology, Sun Yat-Sen University Cancer Center, 651 East Dong Feng Road, Guangzhou 510060, People's Republic of China

2 State Key Laboratory of Oncology in South China, Sun Yat-Sen University Cancer Center, Guangzhou 510060, People's Republic of China

3 Department of Breast Disease, Maternal and Children Metabolic-Genetic Disease Key Laboratory of Guangdong Women and Children Hospital, Guangzhou 510623, People's Republic of China

4 Department of Laboratory Medicine, The First Affiliated Hospital of Sun Yat-Sen University, Guangzhou 510080, People's Republic of China 


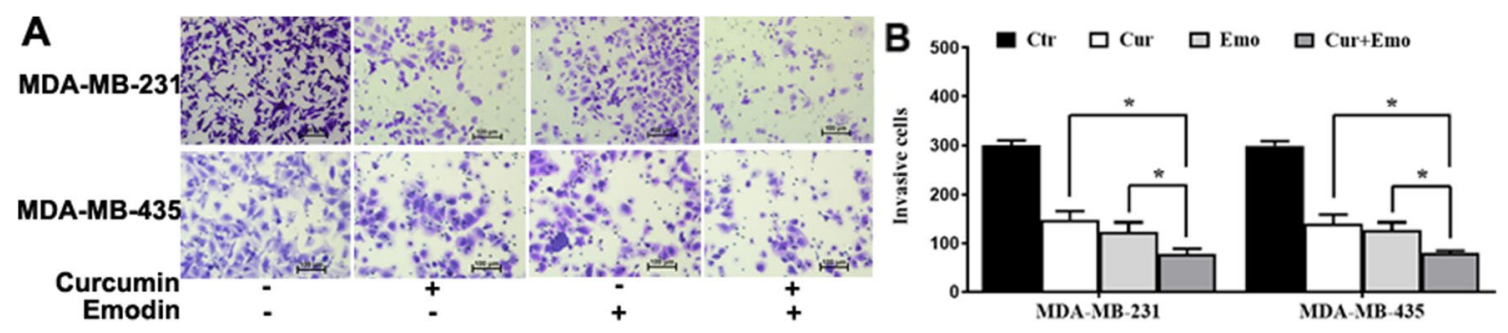

Fig. 3 Curcumin and emodin suppress breast cancer cell invasion. a Representative microscopic fields of invasive cells on the bottom of Matrigel-coated transwell cell culture chambers. MDA-MB-231 cells were treated with $30 \mu \mathrm{M}$ curcumin, $80 \mu \mathrm{M}$ emodin, or both; MDAMB-435 cells were treated with $34 \mu \mathrm{M}$ curcumin, $70 \mu \mathrm{M}$ emodin, or both for $24 \mathrm{~h}$. b Quantification of cell invasion was performed by counting the number of invasive cells. Cells pretreated with curcumin, emodin, or both were seeded onto Matrigel-coated transwell plates and cultured for $24 \mathrm{~h}$. After removing the non-migratory cells, the migratory cells on the bottom side of the membrane were counted. The results presented are the average of three experiments each expressed as the mean \pm SD. $* P<0.05$

Publisher's Note Springer Nature remains neutral with regard to jurisdictional claims in published maps and institutional affiliations. 